\title{
Glutathione S-transferase (GST) gene expression profiles in two marine bivalves exposed to BDE-47 and their potential molecular mechanisms*
}

\author{
LI Fei (李斐) ${ }^{1}$, WU Huifeng (吴惠丰) $)^{1, * *}$, WANG Qing (王清) ${ }^{1}$, LI Xuehua (李雪花) ${ }^{2}$, \\ ZHAO Jianmin (赵建民) ${ }^{1}$ \\ ${ }^{1}$ Key Laboratory of Coastal Zone Environmental Processes and Ecological Remediation, Yantai Institute of Coastal Zone \\ Research (YIC), Chinese Academy of Sciences; Shandong Provincial Key Laboratory of Coastal Zone Environmental Processes, \\ Yantai 264003, China \\ ${ }^{2}$ Key Laboratory of Industrial Ecology and Environmental Engineering (MOE), School of Environmental Science and Technology, \\ Dalian University of Technology, Dalian 116024, China
}

Received May 26, 2014; accepted in principle Sep. 1, 2014; accepted for publication Sep. 19, 2014

(C) Chinese Society for Oceanology and Limnology, Science Press, and Springer-Verlag Berlin Heidelberg 2015

\begin{abstract}
Glutathione S-transferases (GSTs) are phase II enzymes that facilitate the detoxification of xenobiotics and play important roles in antioxidant defense. We investigated the expression patterns of seven Venerupis philippinarum GSTs (VpGSTs) and four Mytilus galloprovincialis GSTs (MgGSTs) following exposure to BDE-47. Differential expressions of the seven $V p G S T s$ and four MgGSTs transcripts were observed, with differences between the hepatopancreas and gills. Among these GSTs, the sigma classes (VpGSTS1, VpGSTS2, VpGSTS3, MgGST1, and MgGST3) were highly expressed in response to BDE-47 exposure, demonstrating their potential as molecular biomarkers for environmental biomonitoring studies. We obtained the three-dimensional crystal structures of VpGSTs and MgGSTs by homologous modeling. A model to elucidate the binding interactions between the ligands and receptors was defined by molecular docking. Hydrophobic and $\pi$ were the most often observed interactions between BDE-47 and the GSTs.
\end{abstract}

Keyword: glutathione S-transferase (GST); Venerupis philippinarum; Mytilus galloprovincialis; 2,2',4,4'-tetrabromodiphenyl ether (BDE-47); molecular docking; biomarker

\section{INTRODUCTION}

Aquatic organisms are frequently exposed to numerous environmental pollutants (Xue and Warshawsky, 2005; Wan et al., 2009). In recent years, research on detoxification and antioxidant enzyme gene expression has become a powerful tool in assessing the ecotoxicological effects of certain chemicals (Won et al., 2011). Glutathione S-transferases (GSTs) are a group of multifunctional enzymes whose major functions involve the detoxification of both endogenous and xenobiotic compounds such as ROS, intracellular transport, biosynthesis of hormones, and protection against oxidative stress (Enayati et al., 2005). GSTs play a critical role in mitigating oxidative stress in all life forms (Lee et al., 2006) and their activities are widely used as biomarkers for environmental monitoring (Shallaja and D'Silva, 2003;
Hoarau et al., 2006; Cunha et al., 2007).

GSTs are found in many prokaryotic and eukaryotic organisms in three intracellular locations: the cytosol, mitochondria, and microsomes (Hayes et al., 2005). In previous studies, multiple specific GST mRNA expressions were investigated in several aquatic organisms following exposure to environmental pollutants (Boutet et al., 2004; Lee et al., 2008; Kim et al., 2010; Nair and Choi, 2011; Won et al., 2011). These studies provided opportunities to explore the correlation of specific GST responses with the detoxification of various toxicants; these were useful to evaluate the potential of different GST isoforms as molecular

\footnotetext{
* Supported by the National Natural Science Foundation of China (No. 21107136) and the International Foundation for Science (No. F/5230-1)

** Corresponding author: hfwu@yic.ac.cn
} 
biomarkers to monitor marine environmental pollution. Venerupis philippinarum and Mytilus galloprovincialis are economically important fishery species in China and are widely distributed in high densities around the heavily polluted Bohai Sea (Liang et al., 2004). They are listed as sentinel organisms in the Mussel Watch Programs launched in China (Conrad et al., 2014). They can accumulate high amounts of contaminants and are used as bioindicators in marine environmental toxicology.

In our previous study, we reported the identification, characterization, and distribution of seven $V$. philippinarum (VpGSTs: VpGSTS1, VpGSTS2, VpGST3, VpGSTO, VpGSTMi, VpGSTM, and $V p G S T R$ ) and four M. galloprovincialis (MgGSTs: $M g G S T \alpha, M g G S T 1, M g G S T 2$, and MgGST3) GSTs from our ESTs database (Zhang et al., 2012). These investigations demonstrated that this species exhibits distinct biochemical and genetic responses when exposed to heavy metals and benzo[a]pyrene (Liu et al., 2011; Zhang et al., 2011a, b), possessing the requisite features of a promising indicator species. GST isoenzymes are considered useful biomarkers in mollusk species (Boutet et al., 2004; Hoarau et al., 2006; Wan et al., 2008, 2009); investigations on GST isoform expression profiles in response to specific environmental pollutants would be helpful in identifying potential biomarkers for future environmental biomonitoring.

In this study, 2,2',4,4'-tetrabromodiphenyl ether (BDE-47) was selected as a typical environmental contaminant in the Bohai Sea (Tian et al., 2010). BDE-47 is one of the dominant PBDE congeners with relatively high concentrations in the aquatic environment and human tissues, although it is no longer produced and constitutes only a minor proportion of historical global PBDE production and usage (Darnerud, 2003; Mazdai et al., 2003; Hites, 2004; Schecter et al., 2007). Based on the analysis of PBDE residue levels in human samples from China, BDE-47 and -153 are the dominant PBDE congeners, accounting for $60 \%$ of the total (Bi et al., 2006). Here, we investigate expression patterns of seven $V p G S T s$ and four $M g G S T s$ following exposure to BDE-47.

We obtained the three-dimensional crystal structures of the VpGSTs and MgGSTs by homologous modeling. A model to elucidate the binding interactions between ligands and receptor interactions was defined by molecular docking-which has become an integral part of many modern structurebased computational chemical simulations (Martinez et al., 2008). Docking methodologies use the knowledge of the three-dimensional structure of a receptor in an attempt to optimize the bound ligand or a series of molecules into the active site. Molecular docking can provide more information on the molecular toxicological mechanism of BDE-47 (Sippl, 2002).

\section{MATERIAL AND METHOD}

\subsection{Animal culture and treatments}

The clams, V. philippinarum (shell length: 3.0$4.0 \mathrm{~cm}$, Zebra pedigrees), and adult mussels, M. galloprovincialis (shell length: $\sim 4 \mathrm{~cm}$ ), were purchased from a local market and acclimatized in aerated seawater at $25^{\circ} \mathrm{C}$ for 10 days prior to BDE- 47 exposure. During the acclimatization period, the clams were fed Chlorella vulgaris Beij, and the water was renewed daily. After acclimatization, the clams and mussels were randomly divided into flat-bottomed rectangular tanks, each containing 20 individuals in $10 \mathrm{~L}$ seawater. During the experiment, the clams and mussels were fed Isochrysis galbana and Platymonas helgolandica, and the seawater was renewed daily.

For the exposure experiment, all 20 clams or mussels per tank were individually treated with the toxicant BDE-47 at $10 \mu \mathrm{g} / \mathrm{L}$ dissolved in DMSO, a concentration previously reported from some heavily polluted sites in the Bohai Sea and the coastal waters of southeast China (Jin et al., 2008; Wan et al., 2008; Pan et al., 2010). The clams and mussels cultured in normal filtered seawater (FSW) and FSW containing $0.002 \%$ DMSO (v/v) were used as the blank and control groups, respectively. During exposure, the clams were fed Isochrysis galbana and Platymonas helgolandica in FSW for $2 \mathrm{~h}$ and then transferred into renewed toxicant-laden seawater daily. The hepatopancreas and gills of six individuals from each treatment were sampled separately after 96-h exposure. The samples were immediately flash-frozen in liquid nitrogen and stored at $-80^{\circ} \mathrm{C}$ for subsequent total RNA extraction.

\subsection{Total RNA extraction}

Total RNA was extracted from different tissues by TRIZOL $^{\circledR}$ Reagent following the manufacturer's directions (Invitrogen life technologies, USA). Firststrand cDNA synthesis was carried out using M-MLV RT (Promega, USA) according to the manufacturer's instructions,oligo(dT)-adaptor(5'-CTCGAGATCGATGCGGCCGCT17-3') as the primer, and the Dnase 
Table 1 Primer sequences used in the present study

\begin{tabular}{|c|c|c|c|c|}
\hline Gene & GenBank accession No. & Oligo name & Sequence $\left(5^{\prime} \rightarrow 3^{\prime}\right)$ & Remarks \\
\hline \multirow[t]{2}{*}{ VpGSTS1 } & AEW46325 & $\mathrm{F}$ & CAGAAGAATTTGGCAGAAGTAG & Real-time PCR \\
\hline & & $\mathrm{R}$ & AAGACAGCAAGATCAGCGAG & \\
\hline \multirow[t]{2}{*}{ VpGSTS2 } & AEW46326 & $\mathrm{F}$ & AAGGCTAAACTTACAGAGGAG & Real-time PCR \\
\hline & & $\mathrm{R}$ & GTGTTTCTTGAGTTCAGGGT & \\
\hline \multirow[t]{2}{*}{ VpGST3 } & AEW46327 & $\mathrm{F}$ & AGATGTATGACAGCGTTGGTG & Real-time PCR \\
\hline & & $\mathrm{R}$ & CTGGTTCGGTTTCCATAGTG & \\
\hline \multirow[t]{2}{*}{ VpGSTO } & AEW46328 & $\mathrm{F}$ & CAAGAAAGGAGGGAAAGGAGAT & Real-time PCR \\
\hline & & $\mathrm{R}$ & CAGCGAAGAAATGAGCATAACG & \\
\hline \multirow[t]{2}{*}{$\operatorname{VpGSTMi}$} & AEW46329 & $\mathrm{F}$ & ACCAGCGGACTTCAGTATCC & Real-time PCR \\
\hline & & $\mathrm{R}$ & TTCCCTGCCTGTCACCTGTT & \\
\hline \multirow[t]{2}{*}{ VpGSTM } & AEW46330 & $\mathrm{F}$ & GACTTCCCAATGTACGAGCTT & Real-time PCR \\
\hline & & $\mathrm{R}$ & ACACTTTCCTGAGCGAGATAC & \\
\hline \multirow[t]{2}{*}{ VpGSTR } & AEW46331 & $\mathrm{F}$ & CCACCACATTGGAAAGAAGGG & Real-time PCR \\
\hline & & $\mathrm{R}$ & ATGGCACCGAGTCAGTTCAG & \\
\hline \multirow[t]{2}{*}{ MgGSTa } & JX485635 & $\mathrm{F}$ & ATCAGGAGGCTGCCAAAGTA & Real-time PCR \\
\hline & & $\mathrm{R}$ & CTACAGCCAACAGGCACTCA & \\
\hline \multirow[t]{2}{*}{$M g G S T 1$} & JX485636 & $\mathrm{F}$ & GGAGCTGGCTCGTATCATGT & Real-time PCR \\
\hline & & $\mathrm{R}$ & TGCAATGGCCATAGACTGAG & \\
\hline \multirow[t]{2}{*}{$M g G S T 2$} & JX485637 & $\mathrm{F}$ & TGAAGCAAAGAAGGCAGAGG & Real-time PCR \\
\hline & & $\mathrm{R}$ & CAAGCCTTTACATCCGGGTA & \\
\hline \multirow[t]{2}{*}{ MgGST3 } & JX485738 & $\mathrm{F}$ & AAGGAAAAGGAAGGGGTGAA & Real-time PCR \\
\hline & & $\mathrm{R}$ & GAAATGGCACCACTCTGGTT & \\
\hline
\end{tabular}

I-treated (Promega) total RNA as a template (Chen et al., 2011).

\subsection{VpGST and MgGST mRNA expressions in different tissues following BDE-47 exposure}

$V p G S T$ and $M g G S T$ mRNA expressions and the response to BDE-47 were measured by quantitative real-time RT-PCR in an Applied Biosystems ${ }^{\circledR} 7500$ fast Real-time PCR System (Applied Biosystems, USA). Details of the primers used for RT-PCR are given in supplemental Table 1. In a 96-well plate, each sample was run in triplicate along with the internal control. The PCR amplification was carried out in a total volume of $50 \mu \mathrm{L}$, containing $25 \mu \mathrm{L}$ of $2 \times \mathrm{SYBR}^{\circledR} \quad$ Green PCR Master Mix (Applied Biosystems), $20 \mu \mathrm{L}$ of the diluted cDNA, $0.5 \mu \mathrm{L}$ of each primer $(10 \mu \mathrm{mol} / \mathrm{L})$, and $4 \mu \mathrm{L}$ of DEPC-treated water. The thermal profile for RT-PCR was $50^{\circ} \mathrm{C}$ for $2 \mathrm{~min}$ and $95^{\circ} \mathrm{C}$ for $10 \mathrm{~min}$ followed by 40 cycles of $95^{\circ} \mathrm{C}$ for $15 \mathrm{~s}$ and $60^{\circ} \mathrm{C}$ for $31 \mathrm{~s}$. At the end of each PCR reaction, a dissociation curve analysis of amplification products was performed to confirm that only one PCR product was amplified and detected. Moreover, each real-time RT-PCR product was purified and sequenced to verify the PCR specificity. After amplification, data acquisition and analysis were performed using Sequence Detection Software v2.3 (Applied Biosystems). The $2^{-\Delta \Delta C t}$ method was chosen as the calculation method. All datasets are given in terms of relative mRNA expression as means \pm standard deviation. One-way analysis of variance (ANOVA) was performed on all data in SPSS 13.0, and $P<0.05$ was considered statistically significant.

\subsection{Homologous modeling and molecular simulation for binding interaction}

Because of its persistence and ability to bioaccumulate, PBDE metabolism in humans and other mammals typically occurs via oxidative pathways, producing hydroxylated PBDEs (HOBDEs) and brominated phenols (Stapleton et al., 2009; Li et al., 2010). HO-PBDEs are formed from the corresponding PBDEs in the presence of cytochrome P450 enzymes (CYPs) in both humans 

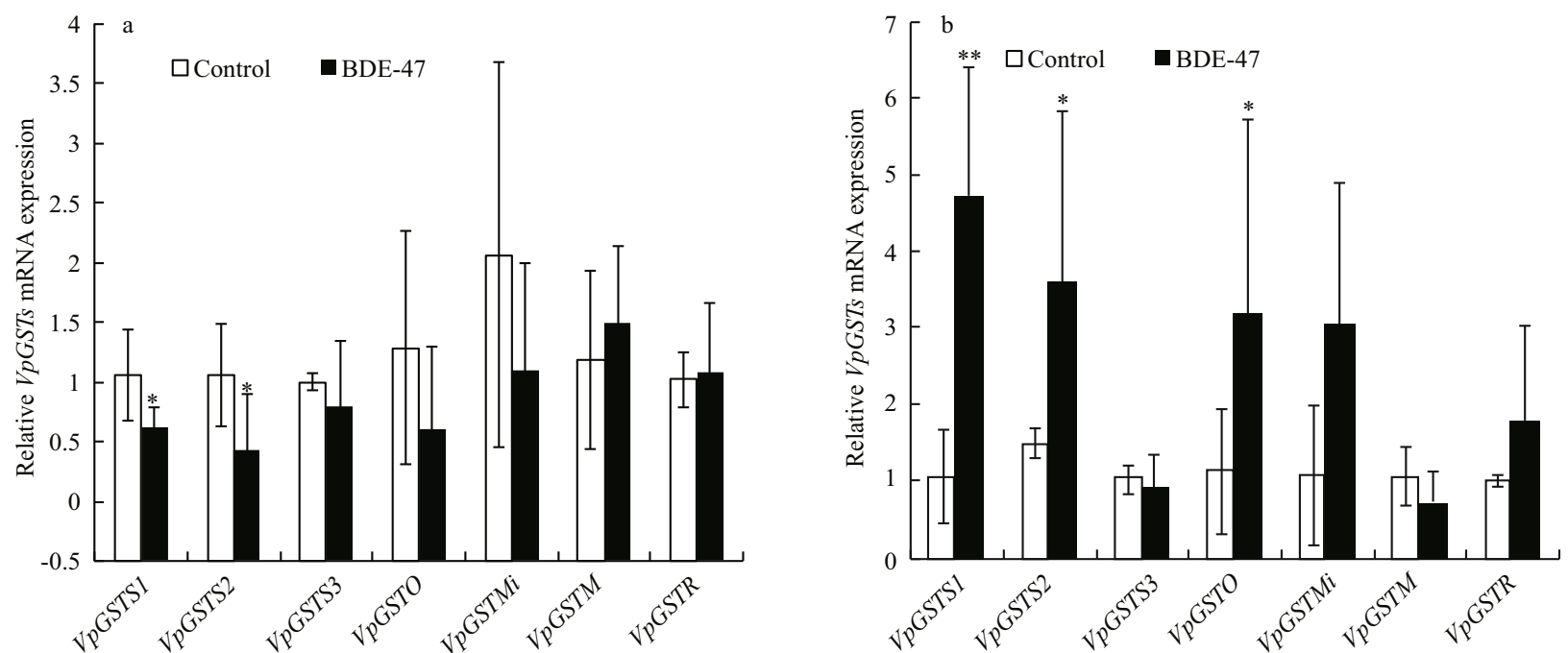

Fig.1 $V p G S T$ isoform (VpGSTS1, VpGSTS2, VpGSTS3, VpGSTMi, VpGSTM, and VpGSTR) mRNA expression profiles in (a) the hepatopancreas and (b) the gills following treatment with $10 \mu \mathrm{g} / \mathrm{L} \mathrm{BDE}-47$ for $96 \mathrm{~h}$

$V p G S T s$ mRNA expression level values were calculated relative to actin expression and are shown as means \pm standard deviations $(n=4)$. Asterisks indicate significant differences $(* P<0.5, * * P<0.05)$ compared with the control.

and animals as well as chemically in the atmosphere. GSTs are responsible for phase II conjugation of many xenobiotics with glutathione and are capable of catalyzing reductive dehalogenation reactions, as evidenced by the reductive dechlorination of DDT by Drosophila GST (Tang and Tu, 1994).

We carried out homologous sequence searches in BLAST, and sequence alignment was completed in Clustal-W (Ramos et al., 2001). A homologous 3D model of $V p G S T S$ and $M g G S T S$ was built on the SWISS-MODEL net server. The binding interactions were studied by CDOCKER, which has been incorporated into Discovery Studio 2.5 (Accelrys Software Inc.) through the Dock Ligands protocol. CDOCKER is an implementation of the docking tool based on the CHARMm force field; its viability has been proven (Wu et al., 2003). In CDOCKER, random ligand conformations are generated through molecular dynamics and a variable number of rigid-body rotations/translations are applied to each conformation to generate the initial ligand poses. Grid-based simulated annealing in the receptor active site further refines the conformations, making the results accurate. From the docking analysis, we gained insights into the interactions between the ligands and the receptor.

\section{RESULT}

\subsection{Effect of BDE-47 on different $V p G S T$ isoform expressions}

GST messenger RNA expressions in $V$. philippinarum hepatopancreas and gills exhibited differential expression patterns following exposure to $10 \mu \mathrm{g} / \mathrm{L}$ BDE-47 for $96 \mathrm{~h}$ (Fig. 1). Among the different sigma class $V p G S T s$ in the hepatopancreas (Fig.1a), the expression levels of VpGSTS1 and VpGST2 were significantly down-regulated (less than two-fold) after being treated with $10 \mu \mathrm{g} / \mathrm{L}$ BDE-47 for $96 \mathrm{~h}$ $(P<0.5)$. However, VpGSTS1 and VpGST2 expression levels in the gills increased 4.47-fold and 2.38-fold $(P<0.05)$, respectively, compared with that of the control group after $96 \mathrm{~h}$ of $10 \mu \mathrm{g} / \mathrm{L}$ BDE-47 exposure (Fig.1b). VpGSTO mRNA expression levels also increased significantly (2.81-fold) under the same treatment (Fig.1b).

\subsection{Effect of BDE-47 on different $M g G S T$ isoform expressions}

MgGST mRNA expressions in BDE-47-exposed M. galloprovincialis exhibited significantly different expression profiles (Fig.2). MgGSTS1 expression in the hepatopancreas increased 4.49 -fold $(P<0.05)$ (Fig.2a) and MgGSTS3 in the gills dropped 0.69-fold $(P<0.5)$ compared with those of the control group (Fig.2b) following exposure to $10 \mu \mathrm{g} / \mathrm{L}$ of BDE-47 for $96 \mathrm{~h}$. However, no significant transcription changes were observed in the other $M g G S T$ isoforms (Fig.2).

The expression profiles of seven $V p G S T$ and four $M g G S T$ genes were investigated to identify promising GST biomarkers. Among the three sigma class $V p G S T s, V p G S T S 2$ was significantly down-regulated 

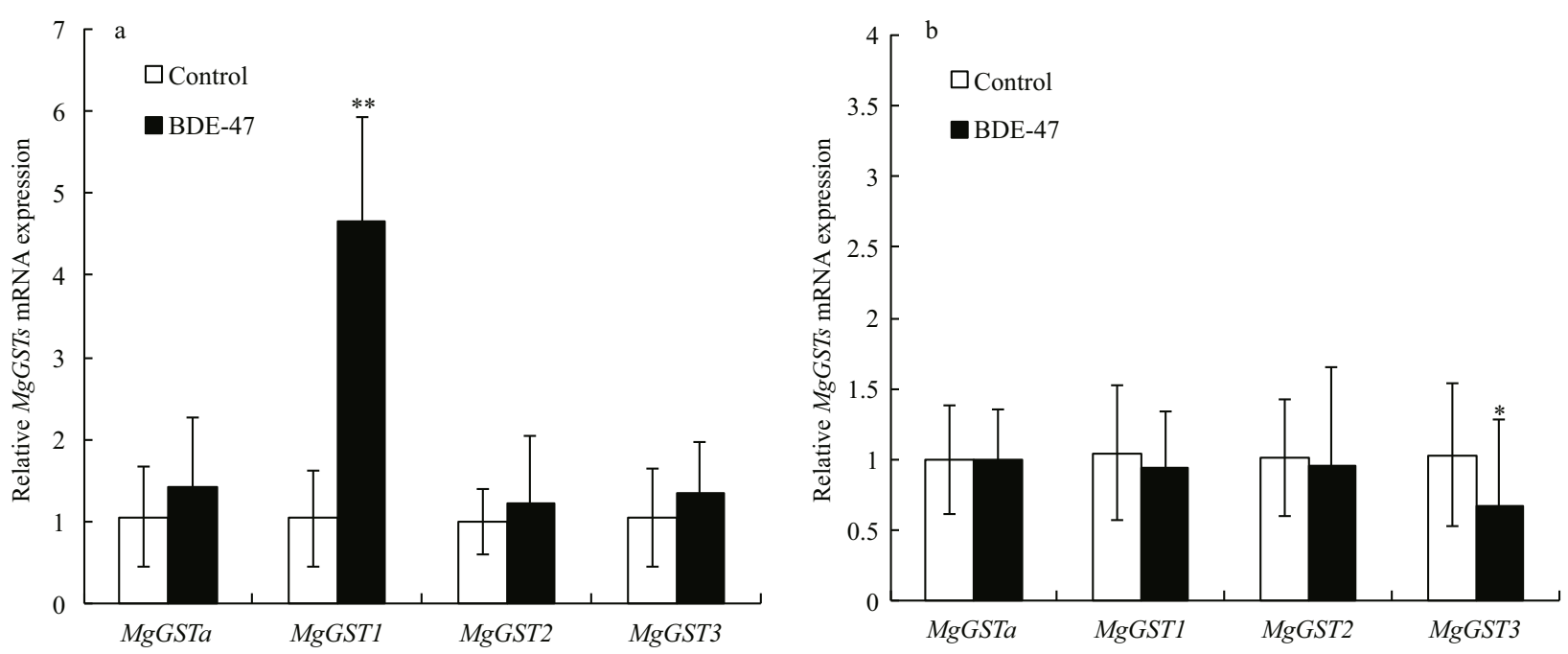

Fig.2 MgGST isoform (MgGSTa, MgGSTS1, MgGSTS2, and MgGSTS3) mRNA expression profiles in (a) the hepatopancreas and (b) the gills following treatment with $10 \mu \mathrm{g} / \mathrm{L}$ BDE-47 for $96 \mathrm{~h}$

The $M g G S T$ mRNA expression level values were calculated relative to actin expression and are shown as means \pm standard deviations $(n=4)$. Asterisks indicate significant differences $(* P<0.5$, ** $P<0.05)$ compared with the control.

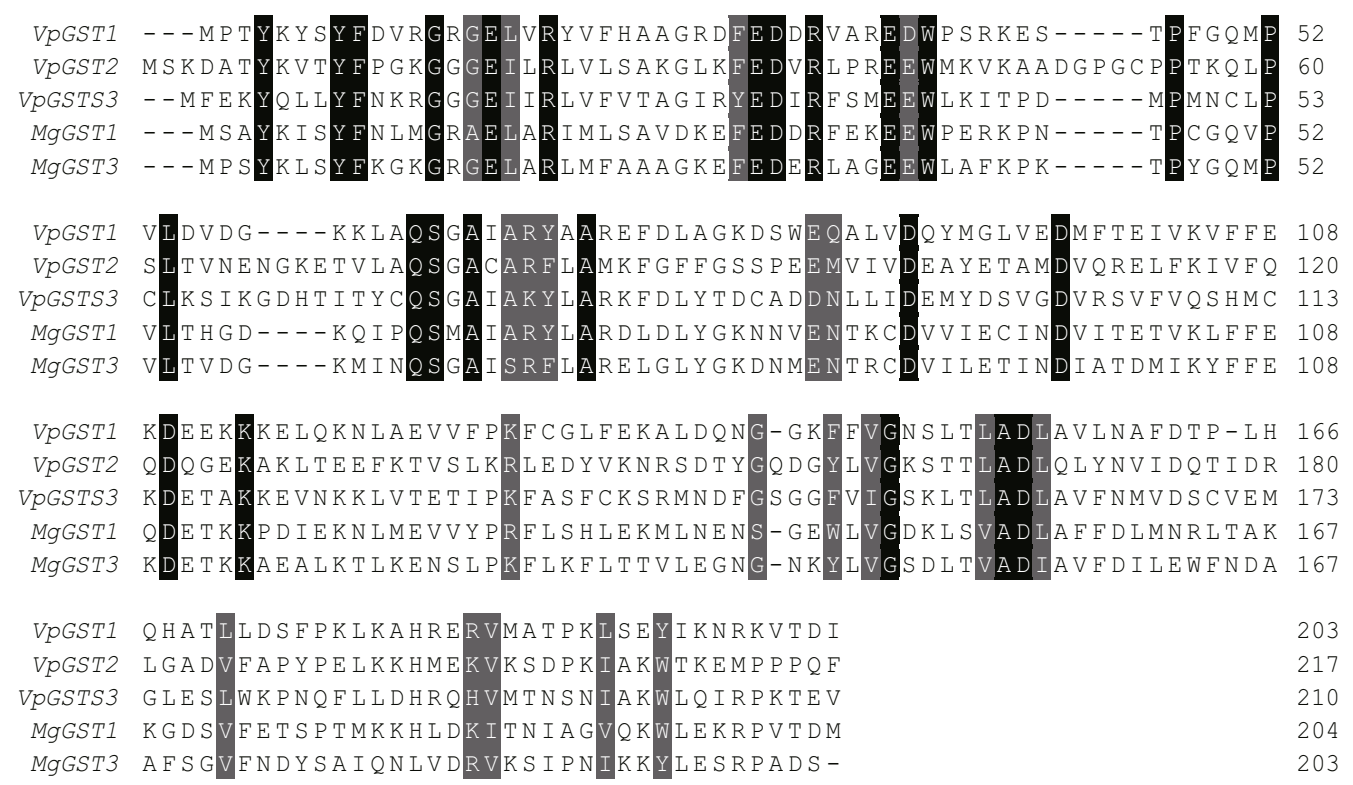

Fig.3 VpGST (VpGSTS1, VpGSTS2, and VpGSTS3) and MgGST (MgGST1 and MgGST3) sequence alignments

in the hepatopancreas, while MgGSTS1 was significantly up-regulated after BDE-47 exposure. VpGSTS1 and VpGSTS2 expression increased dramatically in the gills, while $M g G S T S 3$ displayed notable decreases $(P<0.5)$.

\subsection{Molecular docking}

Homologous sequence searches were again carried out in BLAST for three VpGSTs (VpGSTS1, VpGSTS2, and $V p G S T S 3$ ) and two MgGSTs (MgGST1 and $M g G S T 3$ ) and the sequence alignment was completed in Clustal-W (Fig.3). The sequence consistency of
VpGSTS1 and MgGST1 was 41.2\% and the sequence similarity was as high as $70.6 \%$.

In this study, VpGSTS1 and MgGST1 were selected to investigate the binding interaction with BDE-47. A homologous 3D model of $V p G S T s$ and $M g G S T s$ was built on the SWISS-MODEL net server. In general, GST isoenzymes can accommodate a broad range of electrophilic substrates. However, some isoenzymes display a relatively high stereoselectivity (deGroot et al., 1996). Each GST isoenzyme subunit contains an active site consisting of two binding sites: the $\mathrm{N}$-terminal domain adopts a beta fold and contains a 

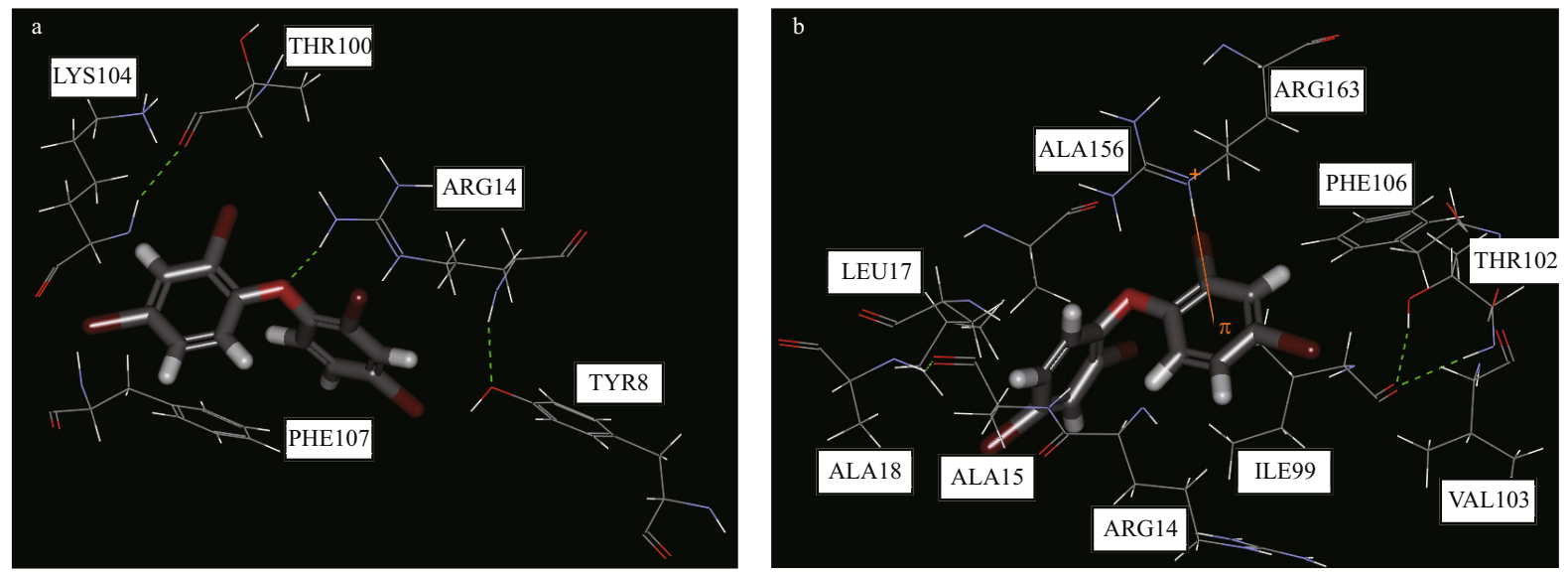

Fig.4 Docking views of (a) VpGSTS1 vs. BDE-47 and (b) MgGST1 vs. BDE-47 in the GST binding sites

Green dotted line indicates H-bonds between BDE-47 and amino acid residues. Orange lines indicate the $\pi$ interactions between BDE-47 and receptors. Gray: carbon; red: oxygen; blue: nitrogen.

GSH binding site (G-site). The C-terminal domain is mostly helical and provides a hydrophobic cavity (H-site) for binding electrophilic substrates (Danielson and Mannervik, 1985; deGroot et al., 1996). Although the G-site is highly homologous in all of the GSTs, there is a great deal of variability in the $\mathrm{H}$-site, which confers the differing substrate selectivity and catalytic properties for each gene class. The docking view of BDE-47 in the VpGSTS1 and MgGST1 binding sites are shown in Fig.4.

Hydrogen-bonding, hydrophobic- and $\pi$-interactions were characteristic of BDE-47 and the GST interactions. At the deep end of the pocket, Arg 14 and Phe107 served as anchoring points for the ligands. An H-bond was observed between the oxygen of BDE-47 and the hydrogen of Arg14 (VpGSTS1 numbering) (Fig.4a). There were also $\pi$ - $\pi$ and $\pi$-cation interactions between the phenyl of BDE-47 and Phe107 and Arg14 (VpGSTS1 numbering) (Fig.4a). $\pi$-cation interactions were also observed in the BDE47 and MgGSTl binding (Fig.4b). However, there were no bindings between BDE-47 and either $V p G S T M i, V p G S T M$, or VpGSTR. From the homology modeling and docking data, the difference in stereoselectivity among GSTs for BDE-47 may be the result of different responses to changes in GST mRNA.

\section{DISCUSSION}

The molecular biological approach in studying potential biomarkers has been widely used as a reliable means to conduct environmental monitoring studies (Hoarau et al., 2006; Rhee et al., 2007). Since GSTs play important roles in both detoxification pathways and the oxidative stress response, they have been widely investigated in ecotoxicology and marine pollution assessment (Boutet et al., 2004; Hoarau et al., 2006; Kim et al., 2010). Therefore, changes in $V p G S T$ and $M g G S T$ expressions observed in $V$. philippinarum and $M$. galloprovincialis exposed to BDE-47 indicate that GSTs might play a defensive role against BDE-47 toxicity. However, as a biomonitor, the information on various classes of $V$. philippinarum and M. galloprovincialis GSTs and their spatial and temporal expression profiles following BDE-47 exposure is currently unavailable.

As important phase II biotransformation enzymes, GSTs catalyze the conjugation of glutathione (GSH) to electrophilic xenobiotics and oxidized components to increase their hydrophilicity and facilitate the excretion of toxicants (Ketterer et al., 1983). Chemical exposure may influence transcription regulatory factors that bind with the promoter region of some GST genes and mediate the transcription of specific GST isoenzymes (Kim et al., 2010). Moreover, accumulation of GSH conjugation with chemicalsan inhibitor of GST expression-might result in significant GST down-regulation (Srivastava et al., 1999).

Seven $V p G S T$ gene expression profiles were studied to identify potential GST biomarkers. In the hepatopancreas, among the VpGSTs, VpGSTS1 and VpGSTS2 were significantly down-regulated, while $V p G S T M$ was significantly up-regulated following exposure to $10 \mu \mathrm{g} / \mathrm{L}$ BDE-47 for $96 \mathrm{~h}$. However, VpGSTS1, VpGSTS2, VpGSTO, and VpGSTMi were significantly up-regulated following BDE-47 exposure. Sigma class GSTs may participate in 
cellular xenobiotic defenses and antioxidant systems in various organisms (Singh et al., 2001; Lee et al., 2008; Won et al., 2011). For example, Tigriopus japonicus GST class sigma (GST-S) is more consistent than other types of GST when exposed to hydrogen peroxide and heavy metals (Lee et al., 2008). A sigma GST from disk abalone (HdGSTS1) also exhibits considerable inducibility by organic contaminants (Wan et al., 2008). Recent studies have shown that sigma GSTs from Chironomus riparius and Perinereis nuntia display great potential as biomarkers for cadmium and silver nanoparticle exposure (Won et al., 2011). The results in the present study were consistent with previous reports, clearly demonstrating that some sigma class $V p G S T$ s are more sensitive to BDE-47 exposure than other GSTS. They also highlight their potential as molecular biomarkers for environmental biomonitoring studies.

GST omega isoenzymes take part in the cellular response to oxidative stress (Board et al., 2000). As reported, the omega GST expressions in Tigriopus japonicus, Takifugu obscurus, Perinereis nuntia, and Haliotis discus discus are significantly induced by $\mathrm{Cd}$ or $\mathrm{Cu}$ exposure (Lee et al., 2008; Wan et al., 2009; Kim et al., 2010; Won et al., 2011). In this work, $V p G S T O$ in the gills increased dramatically in response to BDE-47. In the case of VpGSTMi, a similar pattern of transcriptional repression was observed following BDE-47 exposure. Microsomal GST is ubiquitously expressed and predominantly located in the endoplasmic reticulum and outer mitochondrial membrane; it is vital for the protection of organisms against agents known to induce lipid peroxidation (Johansson et al., 2010). Furthermore, many organisms overexpress GSTs on exposure to chemicals (Hayes et al., 2005).

MgGSTS1 expression in the hepatopancreas increased significantly, while MgGSTS3 in the gills dropped after 96-h exposure to $10 \mu \mathrm{g} / \mathrm{L}$ of BDE-47. $M g G S T$ mRNA expressions in BDE-47-exposed $M$. galloprovincialis exhibited significantly different expression profiles. Of the four $M g G S T S$, the sigma class (MgGST1) was more sensitive to BDE-47 exposure than the other GSTs.

Taken together, our results show that BDE-47 exposure caused differential expressions in the seven $V p G S T s$ and four MgGST1 transcripts. The selective up- or down-regulation of $V p G S T$ gene expression highlights the fact that these isoenzymes probably play divergent physiological roles during the detoxification of various pollutants in $V$.philippinarum and M. galloprovincialis. Among these GSTs, the sigma classes (VpGSTS1, VpGSTS2, VpGSTS3, $M g G S T 1 i$, and $M g G S T 3$ ) were highly expressed in response to BDE-47 exposure, demonstrating their enormous potential as molecular biomarkers for environmental biomonitoring studies.

\section{CONCLUSION}

In summary, we investigated the expression patterns of seven $V p G S T s$ and four $M g G S T$ f following exposure to BDE-47. The three-dimensional crystal structures of the $V p G S T s$ and $M g G S T s$ were obtained by homologous modeling. From the molecular docking study, hydrogen-bonding, hydrophobic- and $\pi$-interactions were characteristic of the interactions between BDE-47 and the GSTs. GST mRNA expressions caused by BDE-47 exposure differed between the hepatopancreas and gills. VpGST transcript expressions appeared to be selectively upor down-regulated, which enhanced our understanding of the antioxidant roles of $V p G S T s$ and their biomarker potential. Among these GSTs, the sigma classes (VpGSTS1, VpGSTS2, VpGSTS3, MgGST1, and $M g G S T 3)$ were highly expressed in response to BDE47 exposure, indicating their good biomarker potential for BDE-47 pollution in the marine environment.

\section{References}

Bi X H, Qu W Y, Sheng G Y, Zhang W B, Mai B X, Chen D J, Yu L, Fu J M. 2006. Polybrominated diphenyl ethers in South China maternal and fetal blood and breast milk. Environ. Pollut., 144: 1 024-1 030.

Board P G, Coggan M, Chelvanayagam G, Easteal S, Jermiin L S, Schulte G K, Danley D E, Hoth L R, Griffor M C, Kamath A V, Rosner M H, Chrunyk B A, Perregaux D E, Gabel C A, Geoghegan K F, Pandit J. 2000. Identification, characterization, and crystal structure of the omega class glutathione transferases. J. Biol. Chem., 275: 24798 24806.

Boutet I, Tanguy A, Moraga D. 2004. Characterisation and expression of four mRNA sequences encoding glutathione S-transferases pi, mu, omega and sigma classes in the Pacific oyster Crassostrea gigas exposed to hydrocarbons and pesticides. Mar. Biol., 146: 53-64.

Chen L L, Mu C K, Zhao J M, Wang C L. 2011. Molecular cloning and characterization of two isoforms of cyclophilin A gene from Venerupis philippinarum. Fish Shellfish Immu., 31: 1 218-1 223.

Conrad S, James O, Reinette S. 2014. An analysis of historical Mussel Watch Programme data from the west coast of the Cape Peninsula, Cape Town. Mar. pollut. Bull., 87: $374-$ 380.

Cunha I, Mangas-Ramirez E, Guilhermino L. 2007. Effects of 
copper and cadmium on cholinesterase and glutathione S-transferase activities of two marine gastropods (Monodonta lineata and Nucella lapillus). Comp. Biochem. Phys. C, 145: 648-657.

Danielson U H, Mannervik B. 1985. Kinetic independence of the subunits of cytosolic glutathione transferase from the rat. Biochem. J., 231: 263-267.

Darnerud P O. 2003. Toxic effects of brominated flame retardants in man and in wildlife. Environ. Int., 29: 841853.

deGroot M J, Vermeulen N P E, Mullenders D L J, denKelder G M D O. 1996. A homology model for rat Mu class glutathione S-transferase 4-4. Chem. Res. Toxicol., 9: 2840.

Enayati AA, Ranson H, Hemingway J. 2005. Insect glutathione transferases and insecticide resistance. Insect Mol. Biol., 14: 3-8.

Hayes J D, Flanagan J U, Jowsey I R. 2005. Glutathione transferases. Annu. Rev. Pharmacol., 45: 51-88.

Hites R A. 2004. Polybrominated diphenyl ethers in the environment and in people: a meta-analysis of concentrations. Environ. Sci. Technol., 38: 945-956.

Hoarau P, Damiens G, Romeo M, Gnassia-Barelli M, Bebianno M J. 2006. Cloning and expression of a GST- $\pi$ gene in Mytilus galloprovincialis. Attempt to use the GST-pi transcript as a biomarker of pollution. Comp. Biochem. Phys. C, 143: 196-203.

Jin J, Liu W Z, Wang Y, Tang X Y. 2008. Levels and distribution of polybrominated diphenyl ethers in plant, shellfish and sediment samples from Laizhou Bay in China. Chemosphere, 71: 1 043-1 050.

Ketterer B, Coles B, Meyer D J. 1983. The role of glutathione in detoxication. Environ. Health Perspect., 49: 59-69.

Kim J H, Dahms H U, Rhee J S, Lee Y M, Lee J, Han K N, Lee J S. 2010. Expression profiles of seven glutathione S-transferase (GST) genes in cadmium-exposed river pufferfish (Takifugu obscurus). Comp. Biochem. Phys. C, 151: 99-106.

Lee K W, Raisuddin S, Rhee J S, Hwang D S, Yu I T, Lee Y M, Park H G, Lee J S. 2008. Expression of glutathione S-transferase (GST) genes in the marine copepod Tigriopus japonicus exposed to trace metals. Aquat. Toxicol., 89: 158-166.

Lee Y M, Seo J S, Jung S O, Kim I C, Lee J S. 2006. Molecular cloning and characterization of theta-class glutathione S-transferase (GST-T) from the hermaphroditic fish Rivulus marmoratus and biochemical comparisons with alpha-class glutathione S-transferase (GST-A). Biochem. Bioph. Res. Co., 346: 1 053-1 061.

Li F, Xie Q, Li X H, Li N, Chi P, Chen J W, Wang Z J, Hao C. 2010. Hormone activity of hydroxylated polybrominated diphenyl ethers on human thyroid receptor-beta: in vitro and in silico investigations. Environ. Health Perspect., 118: $602-606$.

Liang L N, He B, Jiang G B, Chen D Y, Yao Z W. 2004. Evaluation of mollusks as biomonitors to investigate heavy metal contaminations along the Chinese Bohai Sea.
Sci. Total Environ., 324: 105-113.

Liu X L, Zhang L B, You L P, Cong M, Zhao J M, Wu H F, Li C H, Liu D Y, Yu J B. 2011. Toxicological responses to acute mercury exposure for three species of Manila clam Ruditapes philippinarum by NMR-based metabolomics. Environ. Toxicol. Pharmacol., 31: 323-332.

Martinez L, Polikarpov I, Skaf MS. 2008. Only subtle protein conformational adaptations are required for ligand binding to thyroid hormone receptors: simulations using a novel multipoint steered molecular dynamics approach. $J$. Phy. Chem. B, 112: 10 741-10 751.

Mazdai A, Dodder N G, Abernathy M P, Hites R A, Bigsby R M. 2003. Polybrominated diphenyl ethers in maternal and fetal blood samples. Environ. Health Perspect., 111: 1 249-1 252.

Nair P M G, Choi J. 2011. Identification, characterization and expression profiles of Chironomus riparius glutathione S-transferase (GST) genes in response to cadmium and silver nanoparticles exposure. Aquat. Toxicol., 101: 550560.

Pan X H, Tang J H, Li J, Guo Z G, Zhang G. 2010. Levels and distributions of PBDEs and PCBs in sediments of the Bohai Sea, North China. J. Environ. Monit., 12: $1234-$ 1241.

Ramos J D A, Nge C, Wah L B, Yan C K. 2001. cDNA cloning and expression of Blo t 11, the Blomia tropicalis allergen homologous to paramyosin. Int. Arch. Allergy Immunol., 126: 286-293.

Rhee J S, Lee Y M, Hwang D S, Lee K W, Kim I C, Shin K H, Raisuddin S, Lee J S. 2007. Molecular cloning and characterization of omega class glutathione S-transferase (GST-O) from the polychaete Neanthes succinea: biochemical comparison with theta class glutathione S-transferase (GST-T). Comp. Biochem. Phys. C, 146: 471-477.

Schecter A, Johnson-Welch S, Tung K C, Harris T R, Papke O, Rosen R. 2007. Polybrominated diphenyl ether (PBDE) levels in livers of US human fetuses and newborns. $J$. Toxicol. Env. Heal. A, 70: 1-6.

Shallaja M S, D'Silva C. 2003. Evaluation of impact of PAH on a tropical fish, Oreochromis mossambicus using multiple biomarkers. Chemosphere, 53: 835-841.

Singh S P, Coronella J A, Benes H, Cochrane B J, Zimniak P. 2001. Catalytic function of Drosophila melanogaster glutathione S-transferase DmGSTS1-1 (GST-2) in conjugation of lipid peroxidation end products. Eur. J. Biochem., 268: 2 912-2 923.

Sippl W. 2002. Development of biologically active compounds by combining $3 \mathrm{D}$ QSAR and structure-based design methods. J. Comput. Aid. Mol. Des., 16: 825-830.

Srivastava S K, Hu X, Xia H, Awasthi S, Amin S, Singh S V. 1999. Metabolic fate of glutathione conjugate of benzo[a] pyrene-(7R,8S)-diol (9S,10R)-epoxide in human liver. Arch. Biochem. Biophys., 371: 340-344.

Stapleton H M, Kelly S M, Pei R, Letcher R J, Gunsch C. 2009. Metabolism of polybrominated diphenyl ethers (PBDEs) by human hepatocytes in vitro. Environ. Health 
Perspect., 117: 197-202.

Tang A H, Tu C P D. 1994. Biochemical-characterization of drosophila glutathione S-transferases D1 and D21. J. Biol. Chem., 269: 27 876-27 884.

Tian S Y, Zhu L Y, Liu M. 2010. Bioaccumulation and distribution of polybrominated diphenyl ethers in marine species from Bohai Bay, China. Environ. Toxicol. Chem., 29: 2 278-2 285.

Wan Q, Whang I, Lee J S, Lee J. 2009. Novel omega glutathione S-transferases in disk abalone: characterization and protective roles against environmental stress. Comp. Biochem. Phys. C, 150: 558-568.

Wan Q, Whang I, Lee J. 2008. Molecular cloning and characterization of three sigma glutathione S-transferases from disk abalone (Haliotis discus). Comp. Biochem. Phys. B, 151: 257-267.

Wan Y, Hu J Y, Zhang K, An L H. 2008. Trophodynamics of polybrominated diphenyl ethers in the marine food web of Bohai Bay, North China. Environ. Sci. Technol., 42: $1078-1083$.

Won E J, Kim R O, Rhee J S, Park G S, Lee J, Shin K H, Lee Y M, Lee J S. 2011. Response of glutathione S-transferase (GST) genes to cadmium exposure in the marine pollution indicator worm, Perinereis nuntia. Comp. Biochem. Phys. C, 154: 82-92.
Wu G S, Robertson D H, Brooks C L, Vieth M. 2003. Detailed analysis of grid-based molecular docking: a case study of CDOCKER-A CHARMm-based MD docking algorithm. J. Comput. Chem., 24: 1 549-1 562.

Xue W L, Warshawsky D. 2005. Metabolic activation of polycyclic and heterocyclic aromatic hydrocarbons and DNA damage: a review. Toxicol. App. Pharm., 206: 7393.

Zhang L B, Liu X L, Chen L L, You L P, Pei D, Cong M, Zhao J M, Li C H, Liu D Y, Yu J B, Wu H F. 2011b. Transcriptional regulation of selenium-dependent glutathione peroxidase from Venerupis philippinarum in response to pathogen and contaminants challenge. Fish Shellfish Imm., 31: 831-837.

Zhang L B, Qiu L H, Wu H F, Liu X L, You L P, Pei D, Chen L L, Wang Q, Zhao J M. 2012. Expression profiles of seven glutathione S-transferase (GST) genes from Venerupis philippinarum exposed to heavy metals and benzo[a] pyrene. Comp. Biochem. Phys. C, 155: 517-527.

Zhang L, Liu X L, You L P, Zhou D, Wang Q, Li F, Cong M, Li L Z, Zhao J M, Liu D Y, Yu J B, Wu H F. 2011a. Benzo(a) pyrene-induced metabolic responses in Manila clam Ruditapes philippinarum by proton nuclear magnetic resonance ('H NMR) based metabolomics. Environ. Toxicol. Pharm., 32: 218-225. 